\title{
Population vulnerability to tsunami hazards informed by previous and projected disasters: a case study of American Samoa
}

\author{
Nathan Wood ${ }^{1}$ (D) . Jeanne M. Jones ${ }^{2} \cdot$ Yoshiki Yamazaki $^{3} \cdot$ Kwok-Fai Cheung $^{3}$. \\ Jacinta Brown ${ }^{4}$. Jamie L. Jones ${ }^{2} \cdot$ Nina Abdollahian ${ }^{2}$
}

Received: 2 February 2018 / Accepted: 18 September 2018 / Published online: 1 October 2018

(C) The Author(s) 2018

\begin{abstract}
Population vulnerability from tsunamis is a function of the number and location of individuals in hazard zones and their ability to reach safety before wave arrival. Previous tsunami disasters can provide insight on likely evacuation behavior, but post-disaster assessments have not been used extensively in evacuation modeling. We demonstrate the utility of postdisaster assessments in pedestrian evacuation modeling for tsunami hazards and use the US territory of American Samoa as our case study. We model pedestrian travel times out of tsunami inundation zones recreated for the $2009 M_{\mathrm{w}} 8.1$ Samoa earthquake, as well as for a probable maximum tsunami zone for future threats. Modeling assumptions are guided by fatality trends and observations of 2009 evacuation behavior, including insights on departure delays, environmental cues, transportation mode, and demographic characteristics. Differences in actual fatalities from the 2009 disaster and modeled population vulnerability suggest that a single set of estimated travel times to safety does not fully characterize evacuation potential of a dispersed, at-risk population. Efforts to prepare coastal communities in American Samoa for future tsunamis may be challenging given substantial differences in wave characteristics and evacuation potential of the probable maximum hazard compared to the 2009 event.
\end{abstract}

Keywords Tsunami $\cdot$ Evacuation $\cdot$ Pedestrian $\cdot$ Disaster $\cdot$ Modeling $\cdot$ American Samoa

\section{Introduction}

Tsunamis are significant threats to coastal communities; therefore, emergency managers are consistently seeking ways to protect people from harm. Efforts to understand population vulnerability to tsunamis have focused on estimating the number and type of people in hazard zones (e.g., Wood et al. 2010), the ability of individuals to reach safety (e.g., Mas et al. 2012; Di Mauro et al. 2013; Fraser et al. 2014; Wood et al. 2015), and strategies to reduce fatalities (Park et al. 2012; Leon and March 2015; Mostafizi et al. 2017).

Nathan Wood

nwood@usgs.gov

Extended author information available on the last page of the article 


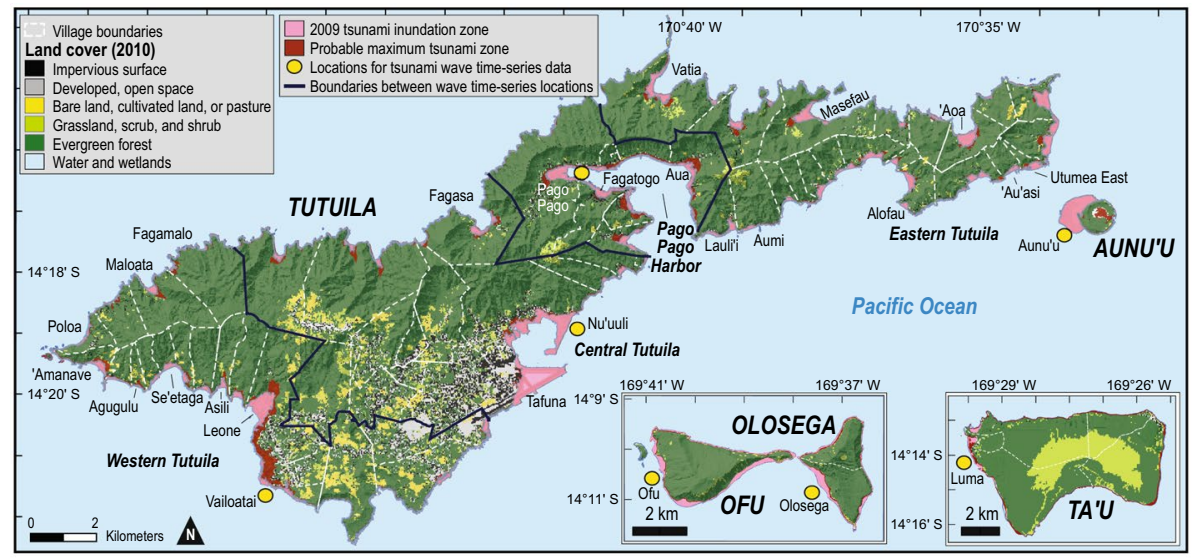

Fig. 1 Study area map of the islands that comprise American Samoa, including 2010 land cover data (Office for Coastal Management 2017) and the tsunami inundation zones associated with the September 29, 2009, $M_{\mathrm{w}} 8.1$ earthquake and a probable maximum tsunami (PMT) hazard zone. Only villages specifically discussed in the article are labeled by name. Offshore locations with modeled wave time series data (yellow circles) are referred to by the closest village. Region names in bold and italicized identify which set of villages are associated with certain wave time series data. Island names are in bold and capitalized, but do not include Rose Atoll or Swains Island due to their lack of available tsunami hazard zones

An important element of understanding evacuation potential is likely evacuation behavior of at-risk individuals, which has been informed by perception surveys (e.g., Fraser et al. 2013; Carlos-Arce et al. 2017) and by post-tsunami studies of observed behavior (e.g., Lachman et al. 1961; Charnkol and Tanaboriboon 2006; Dudley et al. 2011; Yun and Hamada 2012; Murakami et al. 2012; Lindell et al. 2015; Apatu et al. 2015; Latcharote et al. 2018). Some evacuation modeling efforts have included variations in evacuation behavior based on author assumptions (Takabatake et al. 2017) and on perception surveys (e.g., Mas et al. 2012; Alabdouli 2015), but there has been little to no effort to include observations of actual evacuation behavior from past disasters at a location.

Islands within the US territory of American Samoa provide an opportunity to leverage experiences from a recent disaster to assess future population vulnerability to tsunamis. On September 29, 2009, a series of large tsunami waves struck American Samoa as a result of the $M_{\mathrm{w}}$ 8.1 Samoa earthquake that occurred at 6:48 am (Samoa Standard Time) approximately $200 \mathrm{~km}$ to the south in the Tonga Trench (Fritz et al. 2011; Gelfenbaum et al. 2011). Tsunami waves killed an estimated 192 people throughout the region (NGDC/WDS 2017) and 35 of the victims were in American Samoa. The five islands and two atolls that comprise American Samoa (Fig. 1) continue to be threatened by future tsunamis generated by earthquakes within the nearby Tonga Trench, as well as by distant tsunamis generated by earthquakes elsewhere in the seismically active Pacific Ocean basin. Human settlement across the territory is located primarily in low-lying areas along the coast and in adjacent valleys across the multiple islands.

The objective of this paper is to characterize population vulnerability to tsunami hazards in American Samoa based on fatality demographics and observations of evacuee behavior from the 2009 disaster, projections of probable maximum tsunami hazards, and pedestrian evacuation modeling. This approach is an advance of other tsunami vulnerability studies that do not incorporate evacuee behavior from recent disasters or have relied on studies from outside of the area of interest. First, we summarize an unpublished internal report 
developed by the American Samoa Department of Homeland Security on observed evacuation behavior and fatality demographics. Second, we summarize tsunami modeling for scenarios that recreate the 2009 disaster and that delineate a probable maximum tsunami (PMT), which is the basis for current risk reduction efforts. Third, we model pedestrian evacuations to estimate the number of people in hazard zones as a function of travel time out of the 2009 and PMT tsunami hazard zones with comparisons to 2009 fatality records. Finally, we discuss the implications of our analysis for outreach and mitigation to increase community resilience to tsunamis in American Samoa. This information provides direct assistance to tsunami planning efforts in American Samoa, but also provides insight on population vulnerability to other coastal communities throughout the world that are threatened by local tsunami hazards.

\section{Observations of the 2009 tsunami in American Samoa}

On October 15, 2009, approximately 2 weeks after the 2009 Samoa earthquake and tsunami disaster, the American Samoa Department of Homeland Security (ASDHS) conducted an investigation on tsunami fatalities (ASDHS 2009). The investigation included a compilation of the demographics of the 35 fatalities in American Samoa and interviews with survivors to summarize evacuee behavior. An internal ASDHS report that summarized this investigation was made available to the authors of this study to support evacuation modeling for future tsunami threats. For privacy purposes, personally identifiable information (e.g., names, addresses, and telephone numbers) was not included in our review.

Demographics of the 35 fatalities in American Samoa indicate that a disproportionate percentage of victims were female (74\%, Fig. 2a), compared to 2010 US Census estimates of American Samoa (50\% female). There was also a disproportionate percentage of older

(a)

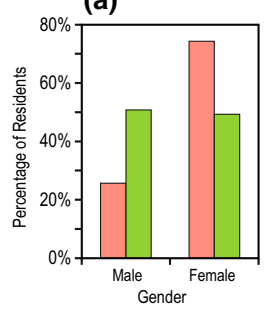

(c)

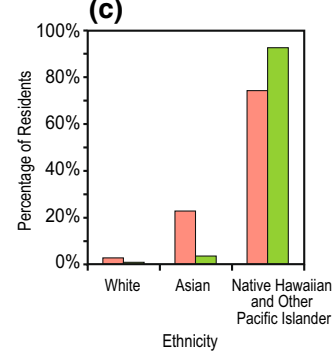

(b)

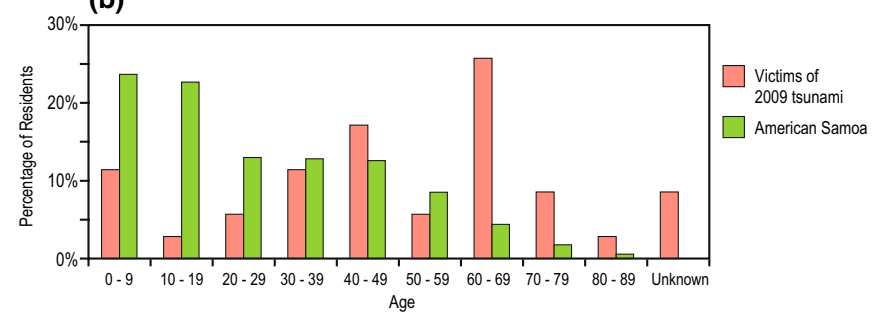

(d)

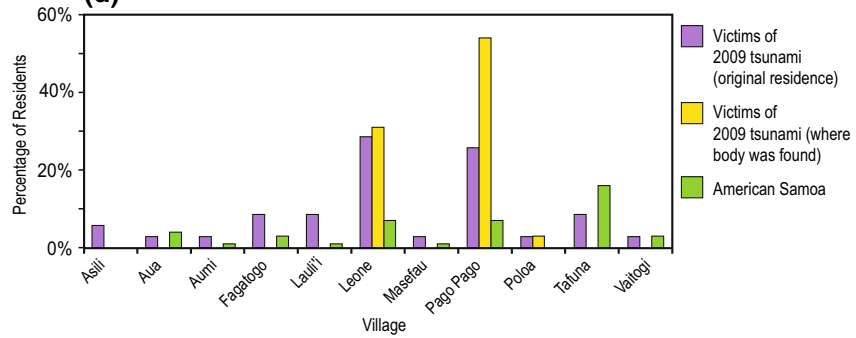

Fig. 2 Demographic attributes of the 35 victims of the 2009 tsunami in American Samoa, relative to 2010 demographic attributes for all territorial residents, including a gender, b age, c ethnicity, and d village where victims either originated from or where bodies were recovered 
victims (Fig. 2b), in that $37 \%$ of victims were 60 years or older, but this age group represents only $5 \%$ of the American Samoa population. Higher mortality rates for older individuals and women are consistent with studies conducted in the aftermath of the 2011 Tohoku earthquake and tsunami in Japan (Murakami et al. 2012; Latcharote et al. 2018).

There was also a disproportionate percentage of victims in American Samoa of Asian ethnicity (23\% of victims compared to $4 \%$ of the territory's population) (Fig. 2c). This is believed to be due to language differences and unfamiliarity with tsunami issues (ASDHS 2009). Disproportionate impacts to minority populations have been documented in other recent tsunami disasters. For example, Pongponrat and Ishii (2018) document how limited access to information, language barriers, and limited social networks created disproportionate impacts to individuals in ethnic minorities in the aftermath of the 2011 Tohoku earthquake in Japan.

American Samoa victims were reported to reside in 11 different villages (Fig. 2d); however, the majority of victims were found in the communities of Leone (31\%) and Pago Pago (54\%). Pago Pago is the territorial capitol of American Samoa and an area of high economic and social activity for the territory. This may partially explain the disproportionate percentage of victims found here relative to the percentage of American Samoa residents that live in Pago Pago (7\%).

The internal ASDHS report includes several insights on evacuation behavior during the 2009 tsunami disaster based on eyewitness accounts. Several of the interviewees stated that they did not have their radio or television turned on at the time; therefore, any warnings sent through these channels would have had limited success. Lindell et al. (2015) surveyed 262 survivors in five American Samoa villages and document that only $4 \%$ of study respondents received their initial warning from the television, but state that $55 \%$ of their respondents did receive their first warning via a radio announcement. Dudley et al. (2011) document that many of the 31 survivors in American Samoa that they interviewed turned on their television or radios after the earthquake to seek out more information.

The ASDHS report, as well as other published studies, notes that many individuals were at their homes getting children ready for school or in transit to school or work, which is understandable given that the 2009 Samoa earthquake occurred at 6:48 am (local time) on a Tuesday. Apatu et al. (2015) document that approximately $70 \%$ of 300 interviewed survivors in American Samoa were at their homes and $82 \%$ of them stated that their family was all together that morning. Dudley et al. (2011) note that some children were at bus stops waiting for their school bus to arrive, and some adults were driving to work. Reese et al. (2011) also document that many people were on their way to work or school in American Samoa at the time of the earthquake.

The internal ASDHS investigation contained several references to people deciding to evacuate based on receding shorelines after the earthquake (which indicates the trough of an imminent tsunami) and not evacuating based on the initial ground shaking alone. This observation was also documented in other American Samoa studies related to the 2009 disaster (Reese et al. 2011; Apatu et al. 2016). Departure delays are supported by a post-disaster reconnaissance effort by the Earthquake Engineering Research Institute (EERI) that was conducted in October and November of 2009 (EERI 2010). In their report, EERI reconnaissance members note that most of the people in American Samoa they spoke to required at least two pieces of information before they decided to evacuate. Feeling the earthquake ground shaking was the first indication, and the shoreline recession was the most common second indication. Others include hearing a bell or alerts from neighbors (EERI 2010). Sound of the approaching waves also served an important role in alerting many residents to evacuate in American Samoa, based on interviews summarized in Dudley et al. (2011). 
Departure delays are supported by survey results summarized in Lindell et al. (2015) of American Samoa survivors of the 2009 tsunami, in which respondents stated taking at least $15 \mathrm{~min}$ after the earthquake to initiate their evacuation. As will be discussed later in this article, first wave arrival ranged from 16 to 27 min across American Samoa communities. Lindell et al. (2015) also document that departures were delayed due to some at-risk individuals seeking additional information from peers, authorities, or news media; locating family members; and packing emergency kits.

Several individuals also were reported in the ASDHS investigation to be in vehicles during the earthquake and therefore unable to feel the ground shaking. Shoreline recession was therefore their only indication of a tsunami, which may also explain the substantial departure delays. Evacuation outreach for local tsunami hazards typically emphasizes pedestrian evacuations (National Research Council 2011); however, several individuals stated that they got into cars after the initial earthquake and used their car horns to alert others. Apatu et al. (2015) note that 16\% of interviewed survivors in American Samoa stated that they evacuated using vehicles and not on foot. Lindell et al. (2015) document even higher vehicular use in American Samoa, including the use of personal vehicles (54\%), another person's car (16\%), public transit (10\%), and emergency vehicles (3\%). A similar study in the aftermath of the 2011 Tohoku tsunami suggests as many as $60 \%$ of interviewed survivors used vehicles to evacuate (Murakami et al. 2012).

Another factor discussed in the internal ASDHS report that led to fatalities is that several individuals refused to evacuate when encouraged to do so by others. There were reports of at least five elderly women in various villages that ignored recommendations to evacuate. Some evacuated after the first wave arrived, but had insufficient time to evacuate before larger second waves arrived. There were also accounts of seeing people running toward the beach to see waves arrive.

\section{Tsunami hazards in American Samoa}

\subsection{Methods}

Tsunami hazard zones for American Samoa include one zone that reconstructs inundation observed after the 2009 Samoa earthquake and another zone that represents a probable maximum tsunami (PMT) for future threats. Geospatial data summarizing both hazards were generated and based on previously published work (Yamazaki et al. 2009; Roeber et al. 2010; Yamazaki et al. 2011). Tsunami hazard zones for the 2009 and PMT scenarios were generated for the American Samoa islands of Tutuila, Aunu'u, and the Manu'a Islands (which include Ofu, Olosega, and Ta'u) (Fig. 1), but not for Rose Atoll or Swains Island due to little (Swains Island) or no human settlement (Rose Atoll) and the lack of reliable topography and bathymetry data.

The seismic source for modeling of the 2009 tsunami inundation in American Samoa is derived from Lay et al. (2010). The earthquake initiated with $M_{\mathrm{w}} 8.1$ outer rise normal faulting, which triggered $M_{\mathrm{w}} 8.0$ thrust faulting on the plate boundary along the Tonga Trench. Figure 3 shows the locations of the normal and thrust faults as well as the waterlevel stations with clear signals of the tsunami. The computation involved a system of two-way nested grids ranging from $30 \operatorname{arcsec}(\sim 900 \mathrm{~m})$ resolution in the South Pacific to $0.3 \operatorname{arcsec}(\sim 9 \mathrm{~m})$ along the shores of American Samoa. Modeling was implemented using the shock capture nonhydrostatic code NEOWAVE (Yamazaki et al. 2009, 2011), which 
Fig. 3 Locations of the normal and thrust faults of the 2009

Samoa earthquake and DART water-level stations in relation to the Samoa Islands

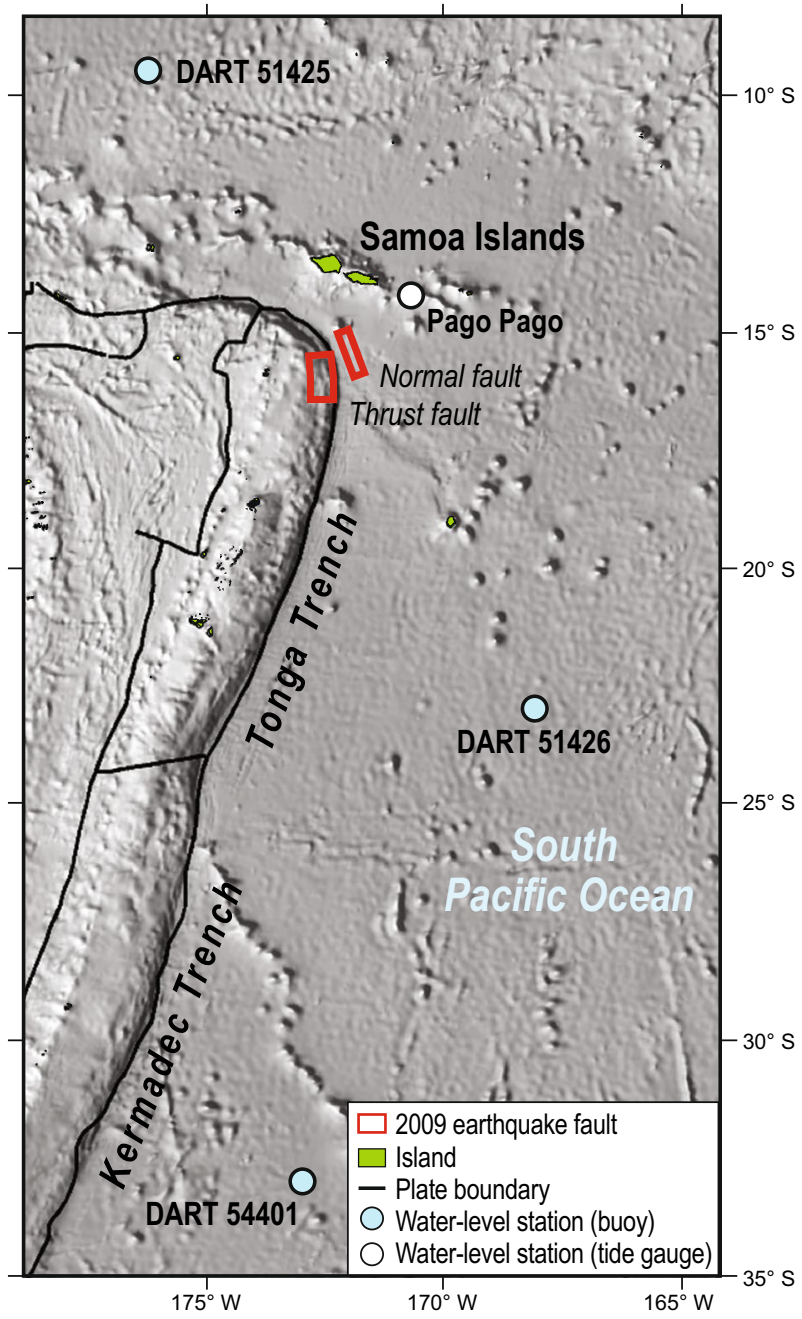

can describe flows over the steep insular slopes as well as tsunami bores on the shallow shelves and reefs. Figure 4 shows good agreement of the computed and recorded tsunami waveforms at the Pago Pago tide gauge and three Deep-ocean Assessment and Reporting of Tsunami (DART) monitoring stations after the initial seismic wave excitations. The tsunami signals at the stations reflect their locations relative to the two faults. Pago Pago and DART monitoring station \#51425, which were closer to the normal fault, recorded a leading trough from it followed by an energetic peak from the thrust fault. The wave sequence is reserved at DART stations \#51426 and \#54401 to the south, highlighting the sensitivity of the tsunami to the source mechanisms. The computed waveforms and inundation zones at the American Samoa coasts provide a baseline to evaluate our evacuation modeling with the information gathered by ASDHS.

The PMT hazard zone was delineated using a composite extreme inundation zone of $M_{\mathrm{w}}$ 9.05 Tonga trench earthquake scenarios, which represent the high end of the $M_{\mathrm{w}} 8.0-9.17$ range suggested by Berryman et al. (2015) as maximum for this subduction zone. The 

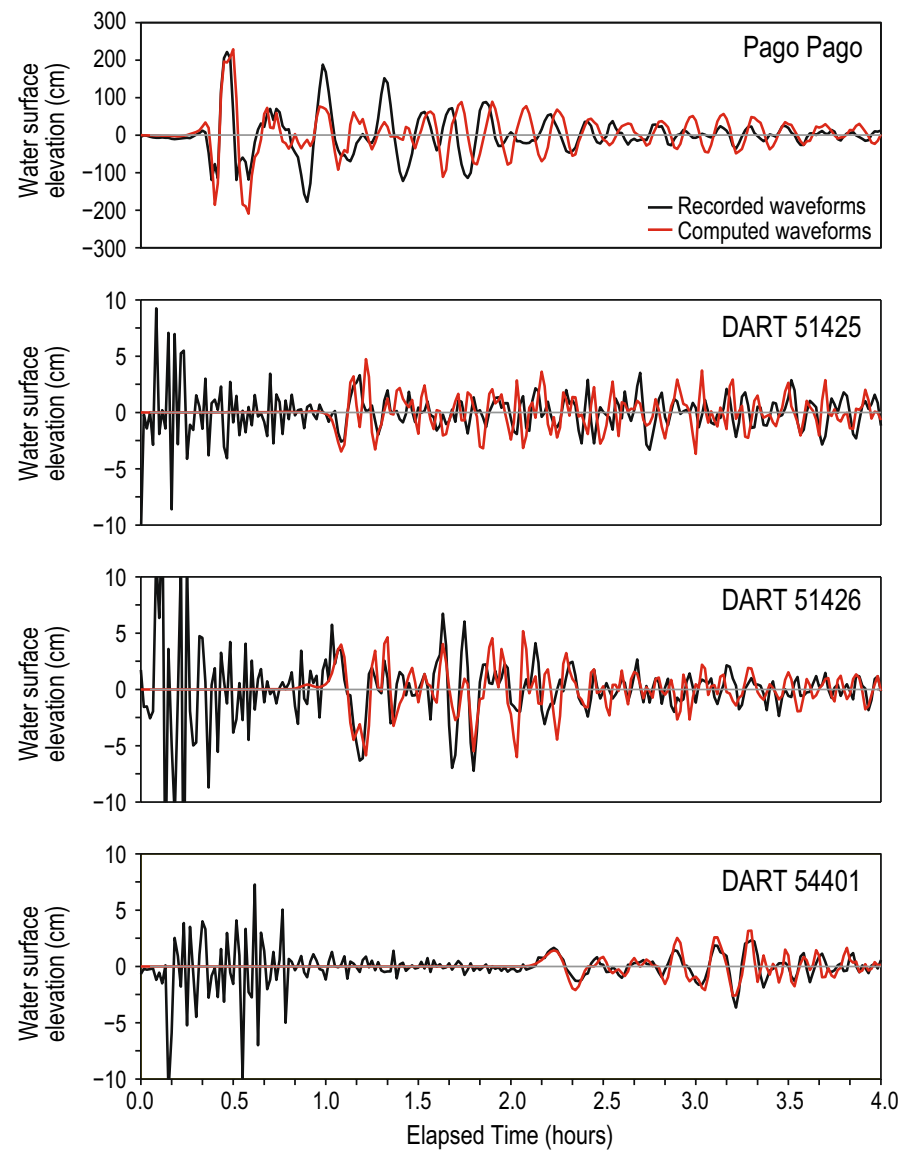

Fig. 4 Comparison of recorded and computed waveforms at DART water-level stations around the 2009 Samoa tsunami source. Locations of water-level stations are shown in Fig. 3

assumed fault is $50 \mathrm{~km}$ wide by $1100 \mathrm{~km}$ long that extends the fully length of the Tonga Trench with subfault geometries and parameters from Gica et al. (2008). Average slip is assumed to be $20 \mathrm{~m}$, which corresponds to 400-1200 years of strain energy accumulation according to published convergence rates of $84-250 \mathrm{~mm} /$ year and the preferred coupling coefficient of 0.2 from Berryman et al. (2015). Two rupture scenarios were considered: one with uniform slip and the other with twice the slip in the up-dip half of the fault. Water level in the PMT modeling was defined at the Mean Higher High Water (MHHW) over the tidal datum plus 25 years of sea-level rise based on formulas in US Army Corps of Engineers (USACOE) guidance (USACOE 2011). Maximum flow depths from both scenarios were aggregated into a single PMT inundation zone and subsequently used in our evacuation modeling for an extreme event.

\subsection{Results}

Time series of estimated water elevation at various points near the American Samoa coast were generated for both the 2009 inundation (Fig. 5a) and the PMT tsunami 
(a) Tsunami from $2009 \mathrm{M}_{\mathrm{w}} 8.1$ earthquake
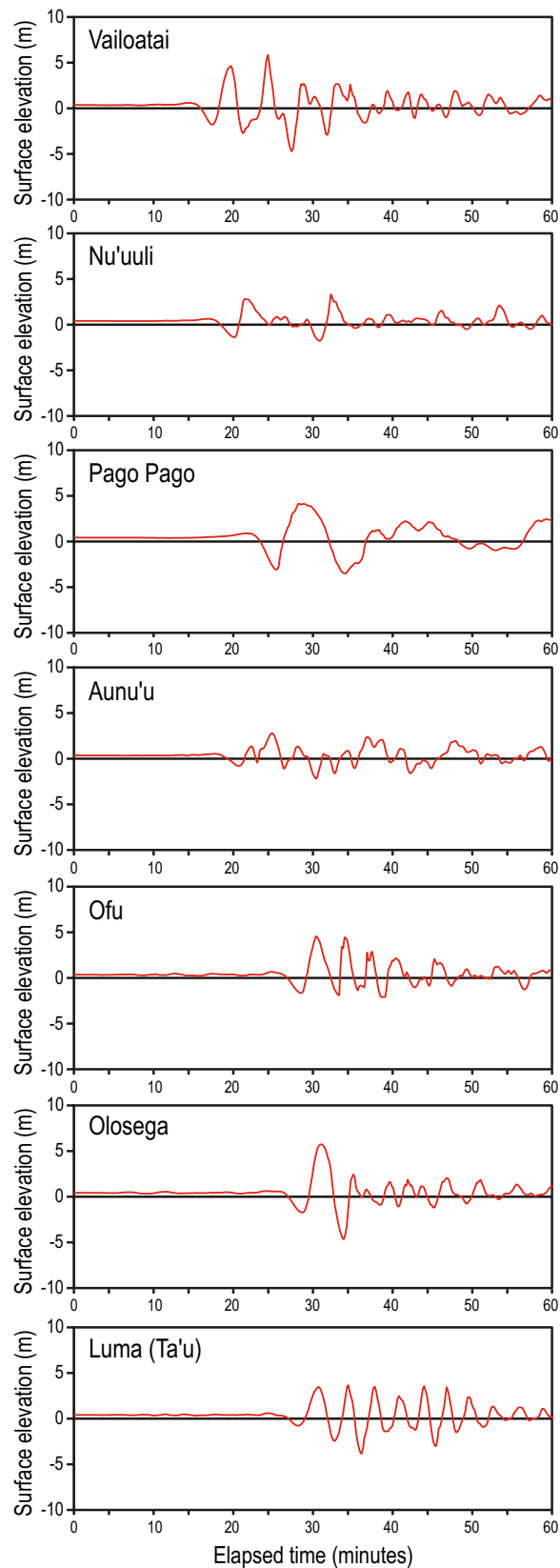

(b) Probable Maximum Tsunami (PMT)
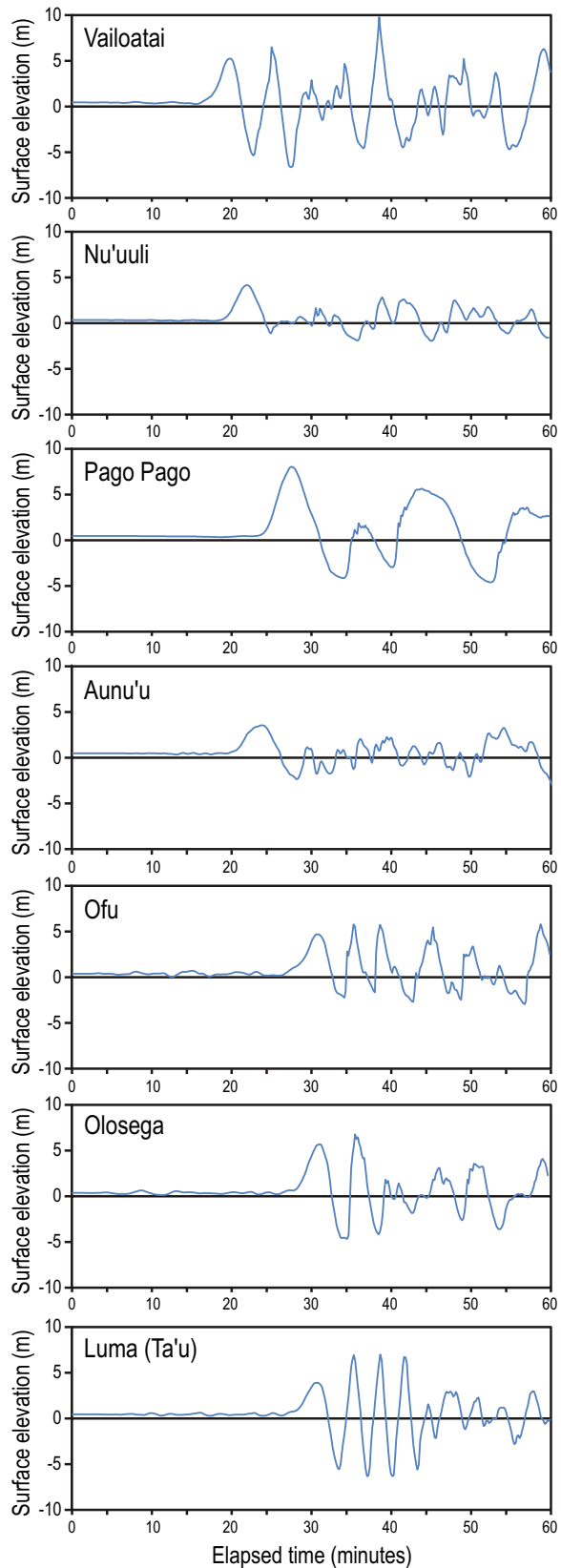

Fig. 5 Estimated time series of wave arrival from a the 2009 event and $\mathbf{b}$ a probable maximum tsunami (PMT) for various locations in American Samoa. Locations of time series data are shown in Fig. 1 and are referenced by the closest village 
hazard scenario (Fig. 5b). For modeling associated with the 2009 tsunami, results indicate that most locations in American Samoa experienced multiple waves with similar heights as opposed to one large wave followed by smaller subsequent waves due to shelf resonance as reported by Roeber et al. (2010). The two exceptions were areas offshore of Pago Pago and Olosega due to the narrower shelves.

The arrival of the first tsunami wave trough after the initial earthquake is estimated to range from 16 min near Vailoatai in western Tutuila Island to 27 min near the Manu'a Islands of Ofu, Olosega, and Ta'u (Fig. 6). The most energetic waves are estimated to arrive ranging from $20 \mathrm{~min}$ near Vailoatai to $31 \mathrm{~min}$ near Ofu, Olosega, and Ta'u. If individuals in 2009 did wait until they saw the shoreline recede before evacuating to high ground, then they would have had from $3 \mathrm{~min}$ (central Tutuila Island) to $6 \mathrm{~min}$ (Aunu'u Island) to reach safety. It should be noted that the initial trough was generated by a normal fault sub-event in the outer rise and cannot be reliably used as a warning sign for future tsunamis.

Modeling results for the PMT scenario suggest several differences from the 2009 event. First, unlike the 2009 results, there is little to no shoreline recession from a preceding wave trough in the PMT results due to thrust faulting along the plate boundary. The primary wave periods are longer due to the increased rupture area. At each of the seven locations selected to show wave characteristics, surface water elevation is relatively constant until it rises in response to the first wave (Fig. 5b). For coastal communities on Tutuila and Aunu'u islands, the time between this initial rise and the peak wave height of the first wave is approximately 3-4 min, similar to the 2009 results (Fig. 6). For coastal communities on Ofu, Olosega, and Ta'u islands, the difference is approximately $8-10 \mathrm{~min}$. Therefore, individuals in tsunami hazard zones may not be alerted of an imminent tsunami from an initial shoreline recession and would only have a few minutes to react if they waited for the water elevation to start to rise. Another difference between 2009 and PMT modeling results is that estimated maximum wave heights will be larger for the PMT scenario, ranging from an $18 \%$ increase near Olosega to a $94 \%$ increase in Pago Pago harbor (Fig. 7).

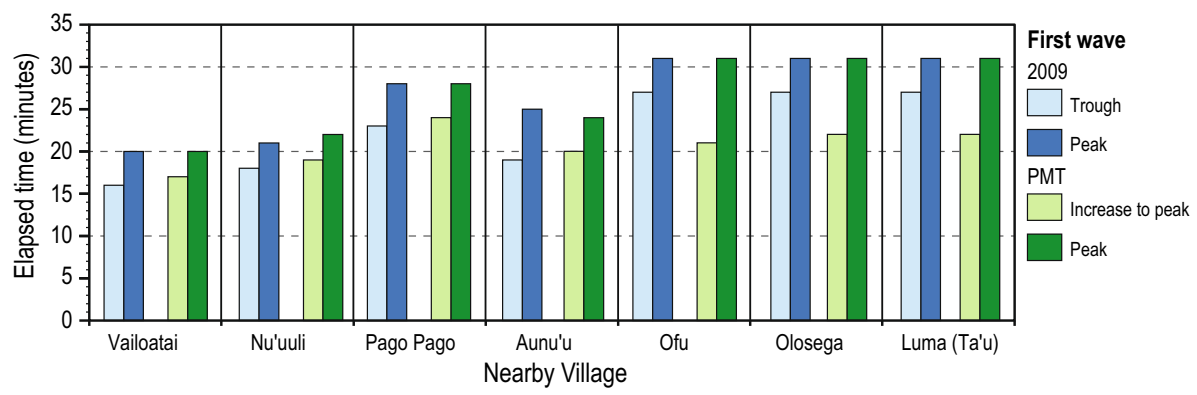

Fig. 6 Estimated elapsed time (in minutes) between onset of the initial earthquake to troughs and peaks for the first tsunami waves associated with the 2009 and PMT scenarios for American Samoa. For the PMT scenario, modeling results indicate little to no trough before wave arrival (Fig. 5b); therefore, bar graphs here note the point in time when surface water elevations begin to rise substantially 


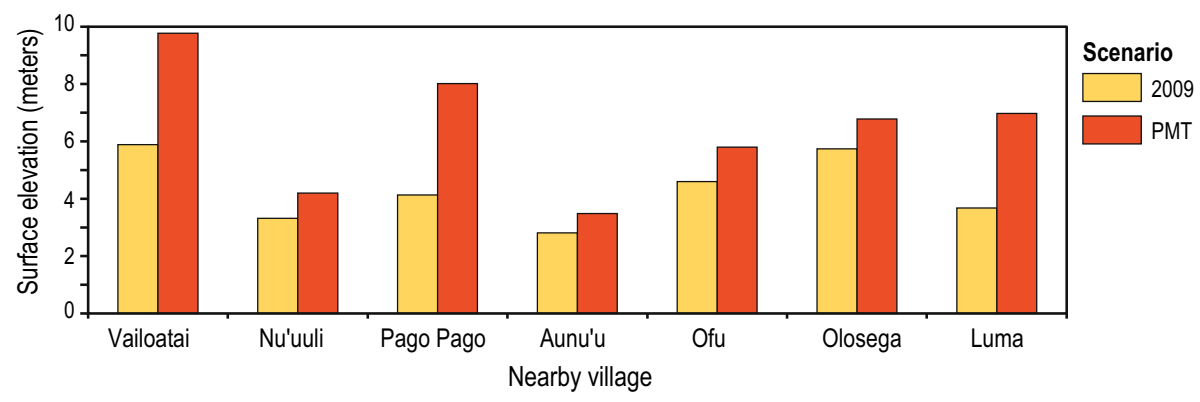

Fig. 7 Estimated surface elevation (in meters) of the maximum wave heights for the 2009 and PMT tsunami scenarios in American Samoa

\section{Pedestrian evacuation potential for tsunami hazards in American Samoa}

\subsection{Methods}

Pedestrian evacuation modeling was done using (a) the 2009 and PMT hazard zones, (b) the estimated number, type, and location of people in these zones, and (c) elevation and land cover characteristics in these zones. We discuss here the various input data and geospatial methods related to estimating population exposure to the 2009 tsunami and to a probable maximum tsunami hazard zone as a function of travel time to safety.

Residential sites (represented as geospatial points) were identified within all census blocks that have any land in the 2009 and PMT hazard zones. Points were determined using 2009 building footprint data (American Samoa Department of Commerce 2016), block-level 2010 Census boundaries and household counts (United States Census Bureau 2011), and manual interpretation of 1-m resolution, red-green-blue (RGB)-band orthorectified imagery taken between 2009 and 2015 (U.S. Department of Agriculture 2017) and Google Street View. The total number of geospatial points to represent households in each census block was matched to the household count in census data. The satellite imagery was used to differentiate households from nonresidential structures (e.g., backyard sheds, businesses). Once residential sites were identified, residential population counts and agerelated demographic attributes at each residence were determined by disaggregating the block-level Census data to all sites within that block. Data collection for the 2010 census took place between April and July, 2010 (United States Census Bureau 2017); however, we felt 2010 data collected 6 months after the 2009 disaster would be a better indication of American Samoa populations than the 2000 data collected 9 years before the event. The 35 lives lost from the 2009 event represent $0.06 \%$ of the total American Samoa population. The authors also are unaware of any significant and permanent population relocation of survivors in the 6 months after the disaster; therefore, the impact of the event on Census counts is assumed to be minimal.

Nonresidential sites included businesses and schools, which were initially based on 2009 geospatial data provided by the American Samoa Department of Commerce (2016). Nonresidential locations and types were updated by manual interpretation of the previously described 2009-2015 imagery and Google Street View. We focused on the number of facilities in tsunami hazard zones and not the number of individuals at each site, given that 
the number of customers at commercial stores and offices, visitors at public venues, and people at schools and medical facilities varies greatly throughout the day, week, and year. The high number of combinations of daytime versus nighttime, weekday versus weekend, and time of year scenarios precludes our ability to choose one scenario over other possibilities. Nonresidential sites were classified as church, community center, school, health care center, hotel, industrial site, office, recreational site, village shelter, or store.

Pedestrian travel times to safety are based on a least-cost distance (LCD) model implemented in ESRI's ArcMap 10.5 geographic information system (GIS) software that takes into account the slope and land cover of an area to calculate the most efficient paths on foot to safety from every location in a hazard zone (Wood and Schmidtlein 2013; Jones et al. 2014). Pedestrian travel times out of the 2009 and PMT hazard zones for American Samoa were estimated using an anisotropic, path distance model where the difficulty of traveling through each location is represented as a cost in terms of increased travel time. Anisotropy incorporates direction of travel, and path distance calculates distances and slopes between cells of varying elevations. Although there were reports of some vehicle use during the 2009 event, we did not model vehicular evacuations given the uncertainty of the number of cars already on the road (referred to as background traffic), the number of cars that were used specifically during the evacuation, and the destinations of all vehicles.

To model pedestrian evacuations, land cover and elevation derived slope data are transformed into raster grids of speed conservation values (SCVs), which represent the proportion of maximum travel speeds that are expected at a location based on local conditions. $\mathrm{SCV}$ s range from 0 (indicating that no travel is permitted through a grid cell) to 1 (indicating that maximum travel speeds are maintained). The modeling then estimates travel directions based on optimal routes of least costs (lowest amount of time in our case), which can be used to estimate overall travel times along an evacuation path for any maximum speed under ideal conditions (i.e., slightly downhill with paved streets). Slope SCVs are based on Tobler's (1993) hiking function, and slopes were derived from 2017, 1-m resolution, LiDAR-derived elevation data (U.S. Department of Agriculture 2017). Land cover SCVs are based on Soule and Goldman's (1972) energy cost terrain coefficients for certain land cover types (Wood and Schmidtlein 2013). Land cover types were characterized using 2.4m, 2010-2011 land cover data produced by National Oceanic and Atmospheric Administration's (NOAA) Coastal Change Analysis Program (C-CAP) (Office for Coastal Management 2017). Ancillary land cover data included roads, building footprints (described earlier), and fences and were merged on top of the C-CAP raster. 2009 road data were provided by American Samoa Department of Commerce (2016) and were further refined by manual interpreting the previously described imagery and Google Street View. Fences were identified in this imagery as well. Artificial driveways that connected building centroids to the nearest road were generated using the ArcMap Near tool (ESRI 2014). Line segments (roads, driveways, and fences) were buffered ( $3 \mathrm{~m}, 2 \mathrm{~m}$, and $1.5 \mathrm{~m}$, respectively) to allow for travel (roads and driveways) or to block travel (fences) and then merged on top of the C-CAP data.

Once a composite land cover raster was created, five distinct SCV values (in parentheses) were used to estimate evacuation times across various land cover types, including impervious surfaces and roads (1.0); developed open spaces, bare inland areas, and driveways (0.9091); cultivated land and pastures (0.833); unconsolidated shorelines (0.556); and water, grasslands, scrubs and shrubs, wetlands, buildings, fences, and forests (0.0). Pedestrian travel was not modeled through forests, wetlands, scrub/shrub, and grasslands (hence the $\mathrm{SCV}=0$ ) due to the thickness of local vegetation and repeated references in the 2009 ASDHS report that people remained on the roads during the evacuation. Finally, cost 
surfaces that integrate land cover and slope variability are converted to maps of pedestrian travel times using maximum travel speed assumptions of a slow walk $(1.10 \mathrm{~m} / \mathrm{s})$, fast walk $(1.52 \mathrm{~m} / \mathrm{s})$, slow run $(1.79 \mathrm{~m} / \mathrm{s})$, and fast run $(3.85 \mathrm{~m} / \mathrm{s})$ (Jones et al. 2014).

\subsection{Results}

\subsubsection{Evacuation potential based on the 2009 tsunami inundation zone}

Based on 2010 population counts, we estimate that there may have been 9246 residents in the 2009 tsunami inundation zone. This is an approximation that may be too high because all individuals accounted for in census data may not have been at their primary residence or may be too low because there could have been other guests at homes or other people in the tsunami zone. If we assume individuals evacuated immediately after the earthquake, then results indicate that every resident in the 2009 tsunami zone would have had sufficient time to reach safety before the arrival of the crest of the first tsunami wave.

Universal application of departure delays of 5, 10, and $15 \mathrm{~min}$ after the earthquake result in 7, 82, and 347 residents, respectively, having insufficient time to evacuate before arrival of the peak wave height. These estimates assume a fast walking speed which is appropriate given the mixed population. Departure delays of 5-10 min may reflect individuals that were motivated to evacuate by the earthquake ground shaking, but who took several minutes to initiate their evacuation. A departure delay of $15 \mathrm{~min}$ or greater may reflect individuals that decided to evacuate only after receiving warning information from an official source, such as the first tsunami information statement from a US tsunami warning center that was sent 15 min after the earthquake (National Research Council 2011). Departure delays of at least 15 min were documented by Lindell et al. (2015).

Several post-disaster reports suggest that many individuals decided to evacuate based on receding shorelines (ASDHS 2009; EERI 2010; Reese et al. 2011; Apatu et al. 2016). If we assume people in a specific village did not evacuate until maximum shoreline recession occurred along the coast of that village (see Fig. 6 on how this timing varies), we estimate that there were 866 people in areas that required travel times greater than the time between estimated shoreline recession and maximum height for the first significant tsunami wave. Again, we assume a fast walking speed as the maximum travel speed. If one varies the assumed travel speed, this estimate ranges from 177 (fast running speed) to 1130 (slow walking speed).

Organized by village, estimated population exposure to the 2009 tsunami as a function of travel time to safety suggests that residents in the majority of villages could have reached safety before wave arrival, even if they waited until they observed the shoreline recede (Fig. 8). Assuming a fast walking speed, the only exceptions are 866 residents among the villages of Leone, Nu'uuli, Aunu'u, Ofu, and Olosega. The additional time that individuals in these areas would require ranges from $2 \mathrm{~min}$ in Leone (Fig. $8 \mathrm{a}$ ) to $17 \mathrm{~min}$ in Nu'uuli (Fig. 8b).

If one assumes a fast running speed, the villages with residents having insufficient time is reduced to Nu'uuli (128 residents) and Olosega (49 residents). These individuals would require an additional two (Olosega) to 4 min (Nu'uuli) to reach safety before wave arrival. However, it is unlikely that many individuals could attain and maintain a fast running speed of $3.85 \mathrm{~m} / \mathrm{s}$; therefore, the use of this travel speed for entire villages is not realistic and included for discussion purposes only. 
(a) Western Tutuila Island

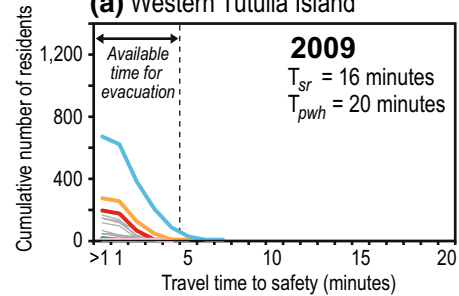

(b) Central Tutuila Island

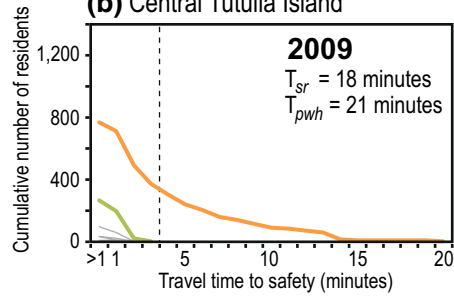

(c) Pago Pago Harbor

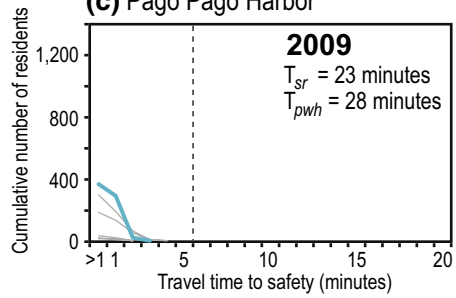

(d) Eastern Tutuila Island and Aunu'u Island

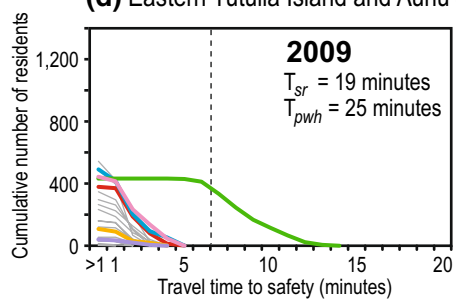

(e) Ofu, Olosega, and Ta'u Islands

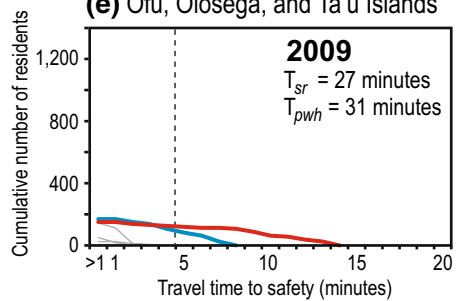

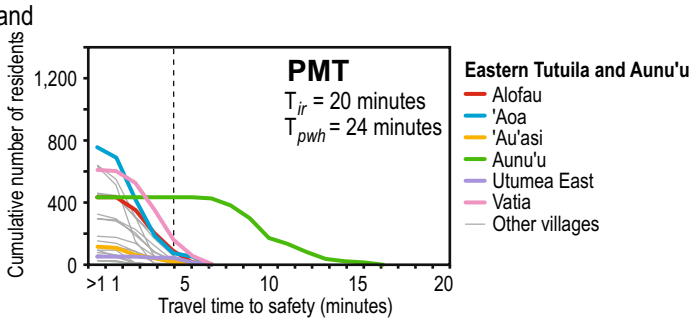
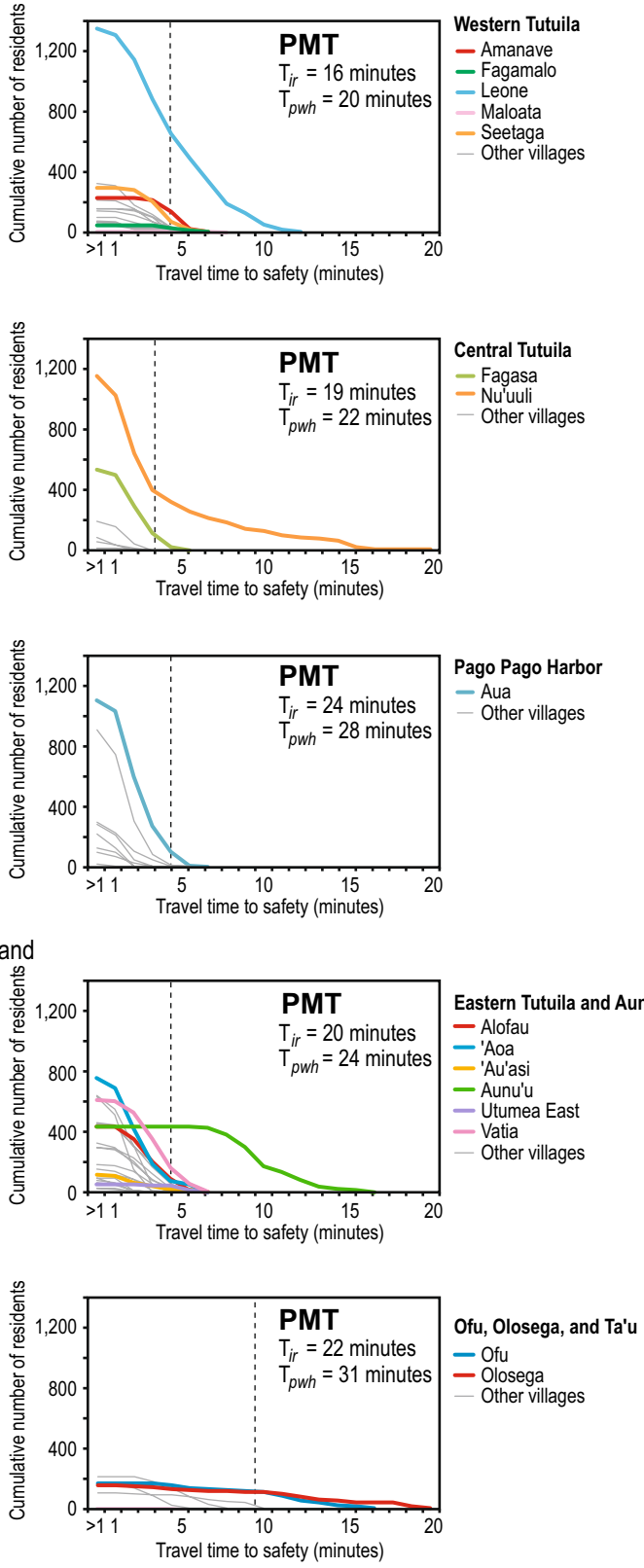

Fig. 8 Cumulative number of residents in 2009 and PMT zones for American Samoa, organized by village and as a function of estimated travel time to safety, based on a "fast walk" travel speed. Estimated elapsed time from the start of the earthquake is noted for the shoreline recession $\left(T_{\mathrm{sr}}\right)$, peak height for the first tsunami wave $\left(T_{\mathrm{pwh}}\right)$, and initial rise of the first wave $\left(T_{\mathrm{ir}}\right)$. Dotted lines note the available time to evacuate to safety if individuals wait to observe the shoreline recession (2009) or initial rise in water elevations (PMT) before initiating their evacuation. Only villages containing residential populations with estimated travel times greater than arrival of the peak wave height for either the 2009 or PMT zones are identified by name in the various graphs 


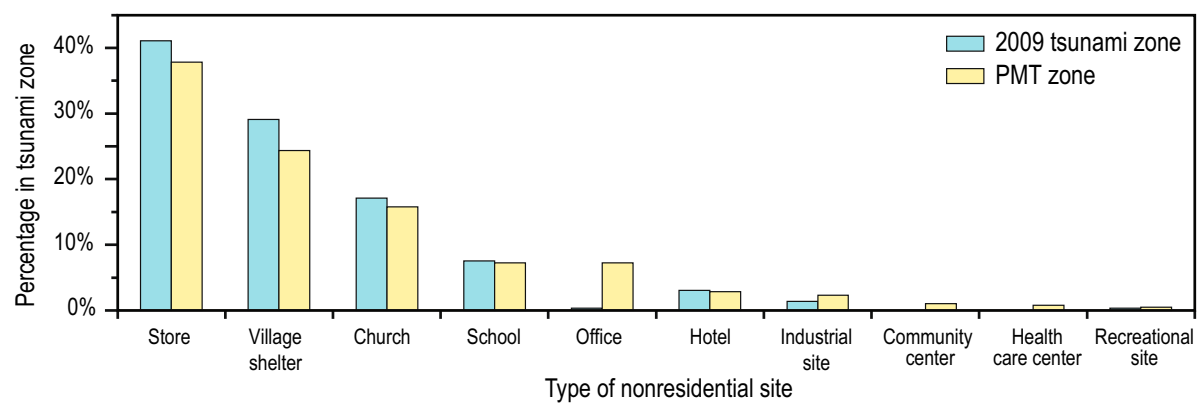

Fig. 9 Percentage of nonresidential sites by type in 2009 and PMT hazard zones relative to the total number of sites in these zones
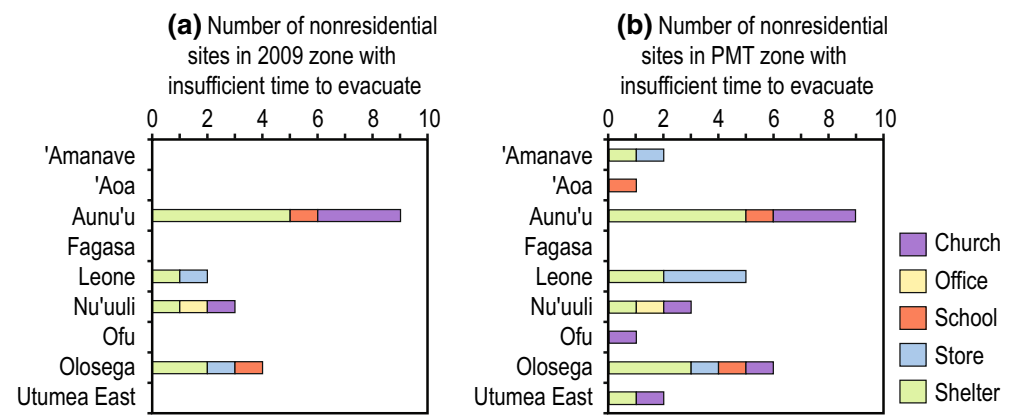

Fig. 10 Number of nonresidential sites (organized by village) in areas where pedestrian travel times are greater than the arrival of the peak wave height for the a 2009 event and b the probable maximum zone. Results are based on the assumptions of a fast walking speed and individuals waiting to see shoreline recession before their departure

There are an estimated 292 nonresidential sites in the 2009 zone, and the primary types are stores, community shelters, and churches (Fig. 9). Eighteen nonresidential sites are in areas where pedestrian travel times are greater than the arrival of the peak wave height, assuming a fast walk and individuals waiting to see shoreline recession before their departure (Fig. 10). These sites include four churches, two elementary schools, an office, nine shelters, and two stores. The 2009 tsunami disaster occurred at 6:48 am local time; therefore, we assume that the number of people at these sites would have been minimal.

Of the 292 nonresidential sites, we estimate that only 15 of them (5\%) may have had substantial on-site populations at that time, including four manufacturing plants, a television station, a yacht club, and nine hotels. All of these businesses are in locations with estimated travel times of 1-3 min for all travel speeds and therefore likely would have had sufficient time to evacuate even if individuals waited until seeing water elevations drop due to the trough of the tsunami. These estimates assume all individuals moved to high ground prior to wave arrival. However, there was one report of a fatality in Pago Pago Harbor when an individual intending to ride out waves aboard his boat was swept off a dock while attempting to untie boat lines (Latitude38 2009). 


\subsubsection{Evacuation potential based on the probable maximum zone}

The probable maximum tsunami (PMT) hazard zone was developed to guide current tsunami education and evacuation efforts in American Samoa; therefore, it is not tied to one specific time of day or population scenario. Based on 2010 population counts, we estimate that there are 15,532 residents in the PMT zone, which represents a $68 \%$ increase over estimates based on the 2009 inundation zones. The majority of villages (all but five of them) have greater numbers of residents in the PMT zone compared to the 2009 zone (Fig. 11a). However, most communities are not estimated to have substantial increases (e.g., less than $100 \%$ increase). The largest increases in the number of residents in tsunami hazard zones are estimated in Aua, Leone, Pago Pago, Nu'uuli, and Vailoatai (Fig. 11), and these increases approximately represent a doubling (Leone, Nu'uuli) or tripling (Aua, Pago Pago) over 2009 exposure estimates. PMT exposure estimates in Vailoatai are eight times the 2009 estimate; however, this substantial increase is due to small numbers ( 38 residents in the 2009 zone compared to 320 residents in the PMT zone).

If all residents initiated their evacuation immediately after the earthquake and did not delay to wait for water elevation changes, then all residents in American Samoa at all travel speeds would have sufficient time to evacuate out of the PMT hazard zone before peak wave arrival. The only exception is seven residents at southern end of a peninsula in Nu'uuli that may need 27 min to evacuate assuming a slow walking speed with peak wave height estimated to arrive $22 \mathrm{~min}$ after the earthquake. If people wait until the water elevation begins to rise quickly in response to the imminent wave peak, then the number of residents with insufficient time to reach safety before wave arrival increases from 866 residents based on the 2009 zone to 1592 residents in the PMT zone (assuming a fast walking speed). The number of residents with insufficient time to evacuate the PMT zone is reduced if assuming a slow running or fast running speed (1173 and 222, respectively).

The number of residents with potentially insufficient time in PMT tsunami hazard zones is not evenly distributed across all American Samoa. In 44 of the 60 villages, all residents are estimated to have sufficient time to reach safety before peak wave height, assuming a fast walking speed and individuals not evacuating until water elevations rise above normal

(a)

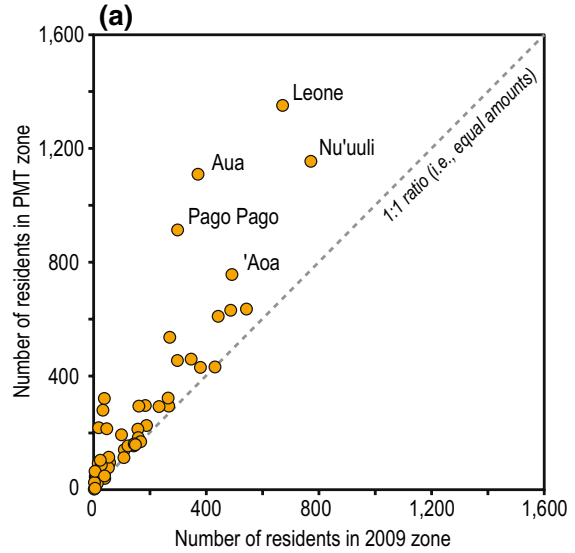

(b)

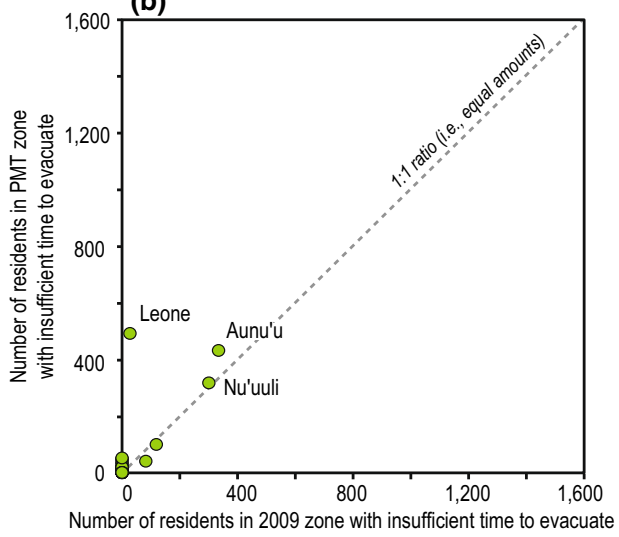

Fig. 11 Scatter plots of resident exposure to tsunami hazards, including a comparison of the number of residents in the 2009 and PMT hazard zones and $\mathbf{b}$ a comparison of the number of residents in the 2009 and PMT hazard zones that may have insufficient time to reach safety, assuming a fast walking speed 
conditions (Fig. 8b). Of the other 16 communities, 11 of them are estimated to have 50 or fewer residents that have insufficient time, two villages have 50-100 residents, and three villages have between 300 and 550 residents (Nu'uuli, Aunu'u, and Leone). The greatest increase over 2009 estimates is estimated for Leone, increasing from 25 residents with insufficient evacuation time in the 2009 zone to 491 residents in the PMT zone (Fig. 11b).

As discussed earlier, demographics of the 35 fatalities in American Samoa indicate that a disproportionate percentage of victims were older than 60 years in age, a finding consistent with other post-tsunami studies conducted elsewhere (Murakami et al. 2012; Latcharote et al. 2018). Demographic analysis of residents in the PMT zone suggests that 1108 of the 15,532 residents in the PMT zone are 60 years in age and older, with the greatest number of older residents in Nu'uuli (90) and Leone (86) (Fig. 12a). Older residents comprise $7 \%$ of the total residents in American Samoa in the PMT zone; however, percentages at the village level range from 0\% (Agugulu) to 100\% (Maloata, although this reflects only 2 residents). For the majority of villages, the percentage of residents in the PMT zone that are 60 years or older is on the order of $4-10 \%$. Evacuation modeling results indicate that all residents, including those 60 years and older, can successfully leave the PMT zone if they began their evacuation immediately after earthquake ground shaking ends and can achieve the assumed travel speeds. If individuals delay their departure from the PMT zone until after water elevations begin to rise, then approximately 239 of the 1109 older residents would have insufficient time to evacuate, assuming a slow walking speed. The highest number of older residents that would have insufficient time to evacuate are in Leone, Nu'uuli, and Aunu'u (Fig. 12b).

There are an estimated 386 nonresidential sites in the PMT zone and the primary types are stores, community shelters, and churches (Fig. 9). The majority of these sites are in locations that would have sufficient time to evacuate. The number of nonresidential sites with insufficient time range from 63 sites (assuming a slow walking speed) to 1 site (assuming a fast running speed). Assuming a fast walking speed for a mixed population, there are 29 nonresidential sites that are estimated to have insufficient time to evacuate, including 13 village shelters, 7 churches, 5 stores, and 1 office (Fig. 10). Three elementary
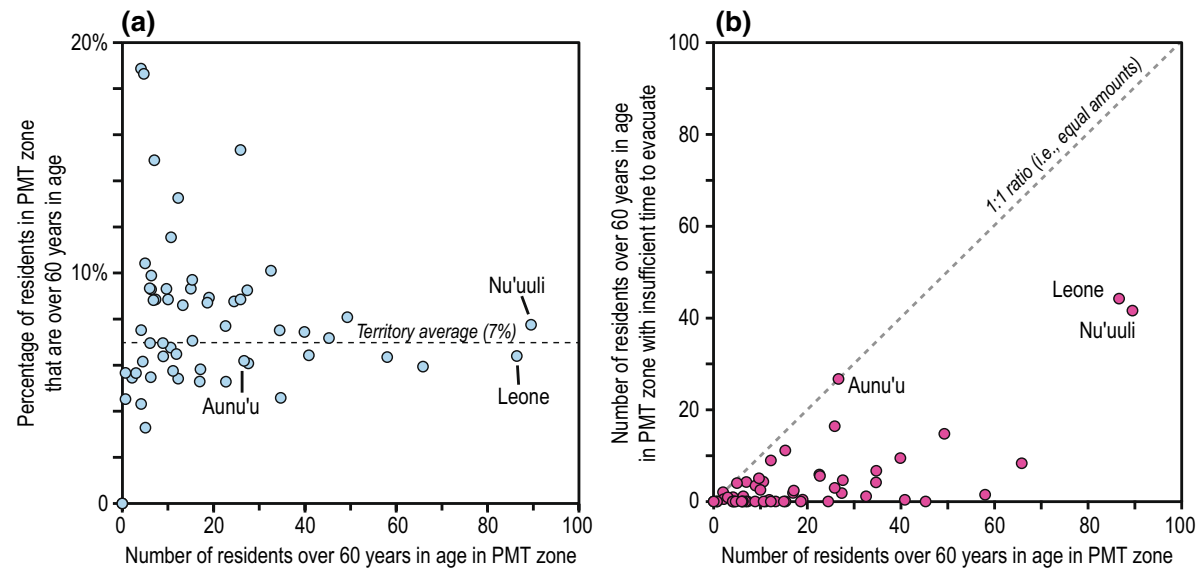

Fig. 12 Tsunami hazard exposure of residents 60 years in age and older, in terms of a the number of these residents in the PMT zone compared to the village percentage that they represent and $\mathbf{b}$ the number of these residents in the PMT zone compared the number of these residents in the PMT zone that may have insufficient time to evacuate, assuming a slow walking speed 
schools are also in this group with estimated travel times ranging from 5 to $13 \mathrm{~min}$. Again, successful evacuations are possible if they began immediately after ground shaking, but less likely if individuals wait to see the water elevations rise above normal conditions.

\section{Discussion}

Developing effective evacuation policies to minimize future loss of life from tsunami hazards requires an understanding of how many people may need to evacuate, how they may behave during an evacuation, and what challenges they may have to reach safety before wave arrival. Our study examines these elements of population vulnerability to tsunami hazards using a case study in American Samoa. In this section, we discuss the implications of our results on tsunami evacuation planning, not only in American Samoa, but also in coastal communities elsewhere throughout the world that are threatened by local tsunamis.

\subsection{The role of departure delays in 2009 evacuation potential}

The influence of evacuation start time on survival rates during a tsunami has been well documented, both in post-disaster assessments (e.g., Yun and Hamada 2012) and in theoretical evacuation modeling (e.g., Fraser et al. 2014). The post-2009 ASDHS report summarized in Sect. 2 as well as other sources (EERI 2010; Lindell et al. 2015) indicates that many at-risk individuals did not instantly evacuate after the earthquake and often did not evacuate until after seeing the shoreline recession related to the imminent wave. While this may be the case for many individuals, our results suggest that foot-based evacuations that were initiated after seeing water elevations decrease cannot alone explain the absence of fatalities in some villages and the overall low fatalities across American Samoa. Our analysis indicates that there were approximately 9000 residents in the 2009 tsunami inundation zone, between 177 and 1130 residents (assuming a fast running and slow walking speed, respectively) in areas that would have required travel times to safety greater than the time between estimated shoreline recession and maximum wave heights, but ultimately only 35 fatalities.

One contributing factor for the difference between 35 fatalities and the high number of individuals with insufficient time to evacuate could be that the number of individuals at residences in the 2009 tsunami zone may not have been as high as the 2010 population count would imply. A substantial number of people may not have been at their homes in the early morning when the event occurred. Given the early morning timing of the event, individuals could have been on their way to work or to school, an assertion that was documented in the 2009 ASDHS report as well as other published studies (e.g., Dudley et al. 2011; Reese et al. 2011; Apatu et al. 2015).

Another potential factor is that some individuals may have decided to evacuate immediately after feeling the initial earthquake (assumed 1 min in duration) or soon after (e.g., after the first official tsunami statement was issued), but before shoreline recession could be observed. Our results suggest that all residents could have successfully evacuated if they left immediately after ground shaking ended. Departure delays of 5, 10, and 15 min after the earthquake results in 7, 82, and 347 residents, respectively, having insufficient time to evacuate, assuming a fast walking speed. Therefore, although there were many reports of at-risk individuals not evacuating until they observed the shoreline recession (ASDHS 
2009; EERI 2010; Lindell et al. 2015), modeling results suggest this was not the case for all individuals.

A third potential factor that explains the low fatalities is that some individuals may have used vehicles to reach high ground. This explanation is supported by multiple references in the ASDHS post-2009 report of individuals in their cars during the evacuation and using their car horns to warn others on the streets. It is unclear if these individuals were already in their cars before the earthquake or were able to get into the cars in the limited time between shoreline recession and peak wave heights. The use of vehicles in American Samoa to evacuate is documented in other studies, but the extent of their use varies considerably, from $16 \%$ of interviewed survivors (Apatu et al. 2015) to $82 \%$ in Lindell et al. (2015). Studies of the 2011 Tohoku disaster indicate similar findings in that Murakami et al. (2012) suggest approximately $60 \%$ of interviewed survivors used vehicles to evacuate.

Finally, the location of fatalities compared to estimated areas with evacuation challenges suggests that modeled travel times to safety alone do not fully characterize evacuation potential. Evacuation modeling results indicate that residents with insufficient time to evacuate if they waited to observe the shoreline recession were concentrated in the villages of Leone, Nu'uuli, Aunu'u, Ofu, and Olosega (Fig. 6). However, aside from Leone, these villages were not where fatalities were recorded (Fig. 2d), and instead, fatalities were associated with villages that had very short estimated travel times to safety (Fig. 8). Fatality demographics indicate a disproportionate percentage of victims that were older and of Asian descent (Fig. 2b, c), suggesting that mobility and language barriers may have been contributing factors. The ASDHS report also had several references to elderly residents ignoring recommendations to leave prior to wave arrival.

\subsection{Changes in population vulnerability to current tsunami threats}

The 2009 Samoa tsunami killed 35 people in American Samoa and the question now before local emergency managers is how destructive future tsunamis could be to their coastal communities. Results presented here coupled with well-documented biases in risk psychology suggest several challenges to increasing resilience to future tsunami threats in American Samoa. Given substantial differences in the 2009 disaster and PMT tsunami threat, successful tsunami preparedness outreach and evacuation training will need to overcome potential anchoring and adjustment, which is a mental heuristic wherein at-risk individuals form attitudes and judgments on what they should do for future events based on what they did in past events (Tversky and Kahneman 1974).

One set of potential differences is the characteristics of tsunami threat itself. PMT inundation modeling suggests that pre-inundation shoreline recession may not occur (Fig. 5), which served as a visual cue for many evacuees in 2009, and instead, water elevations may rise only when the wave crest is approaching the shoreline. PMT inundation modeling also suggests that maximum wave heights may be higher than those observed in 2009 (Fig. 9), creating larger areas of inundation. Therefore, individuals that returned home to see little to no damage in 2009 may be less inclined to evacuate from future tsunamis despite the potential for greater damage associated with the PMT.

The increase in size of potential inundation areas results in more residents in hazard zones ( 6000, 68\% increase) and introduces greater evacuation challenges in several villages. The largest increases in resident exposure are concentrated in only a few villages (Aua, Leone, Pago Pago, Nu'uuli, Vailoatia) (Fig. 8); however, aside from Nu'uuli and Vailoatia, these are villages that had several fatalities during the 2009 event (Fig. 2d). 
If individuals wait for the visual cue of shoreline recession before evacuating as it was reported in 2009, then the number of residents without sufficient time to reach safety doubles with the PMT zone. Seven percent of the at-risk population in the PMT zone are also 60 years in age or older, which was disproportionally represented in 2009 fatalities (Fig. 2b), and modeling results suggest that 239 of them may have insufficient time to evacuate if they waited for water elevations to rise before evacuating (Fig. 12).

Another potential challenge in future tsunami outreach is preparing people to properly evacuate if they are not at their homes. The early timing of the 2009 event likely resulted in most people being either at home or in transit to work or schools. Therefore, at-risk individuals may anchor future behavior to what they would do from their home. Modeling results indicate many additional nonresidences in the PMT zone, including churches and elementary schools. All sites are in locations with sufficient time if evacuations began after the earthquake, but several would not be if departures were delayed (Fig. 10b).

Although the number of people in tsunami hazard zones has increased since the 2009 disaster, tsunami preparedness programs may have greater success than before 2009 now that individuals can readily remember the recent disaster, referred to as an availability heuristic in the risk psychology literature (Tversky and Kahneman 1974). The 2009 disaster may influence at-risk individuals to prepare for future events, even though the likelihood of future events is low. Alternatively, some individuals may think future events are not likely given the recent disaster, a belief referred to as gambler's fallacy or "law of small numbers" (Tversky and Kahneman 1971), which could lead them to not prepare for future events.

\subsection{Insights from evacuation modeling for potential risk reduction strategies}

Given the high number of residences and nonresidences in the PMT zone, efforts to minimize impacts from future tsunamis is a significant topic for local emergency managers. Results demonstrate that eliminating departure delays allows for all at-risk individuals to reach safety before estimated wave arrivals (Fig. 8). All individuals immediately leaving after the earthquake ground shaking ends is ideal and a worthy preparedness goal; however, it may not be realistic given the various delays related to warning confirmation, unfamiliar surroundings, and caregiver status. Several studies from various tsunami disasters have documented departure delays (e.g., Yun and Hamada 2012; Lindell et al. 2015). Therefore, in addition to sustained outreach and evacuation training to minimize departure delays, attention turns to what other risk reduction efforts could support at-risk individuals in their efforts to reach safety.

Evacuation modeling results indicate there is not one single solution for reducing risk. To demonstrate this variability, we focus on the communities of Leone, Nu'uuli, and Aunu'u (Fig. 13), which have substantial numbers of residents and businesses in areas where the estimated pedestrian travel time is higher than the amount of available time, assuming individuals wait to see water elevations rise (Fig. 8). In Leone and Aunu'u, maximum pedestrian travel times are on the order of 10-14 min, but largely due to dense forest vegetation that restricts evacuations to a limited number of roads out of hazard zones (Fig. 13a, c). Potential mitigation in these communities, as well as other coastal communities with similar dense vegetation, could include the creation and sustained maintenance of new foot paths to high ground.

The creation of new egress options would be less successful in communities such as Nu'uuli, given its long, peninsular shape (Fig. 13b). There are several egress options along the boundary of the hazard zone in Nu'uuli, and evacuation challenges are simply an issue 
(a) Leone

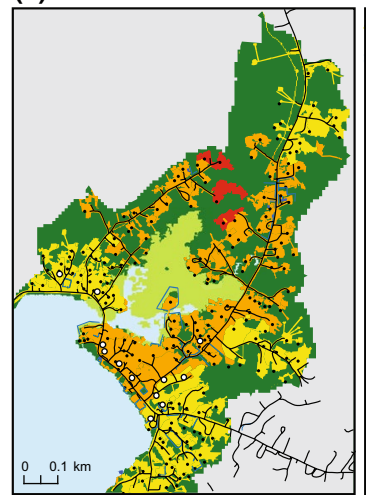

(b) Nu'uuli

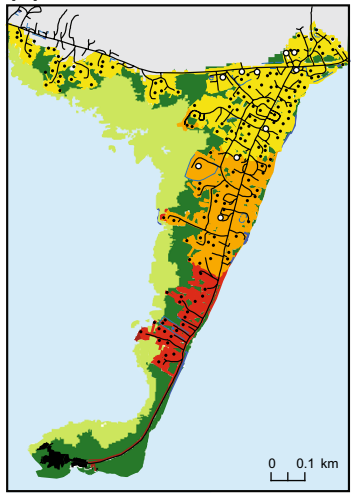

- Fence (barrier)

- Roads

$\square$ Water

Wetland (barrier)

Forest (barrier)

- Residential site

- Nonresidential site
Estimated pedestrian travel time

$\square 0$ (outside of hazard zone)

$\square 1$ - 4 minutes

$\square 5$ - 9 minutes

$10-14$ minutes

15 - 19 minutes

20 - 25 minutes (c) Aunu'u

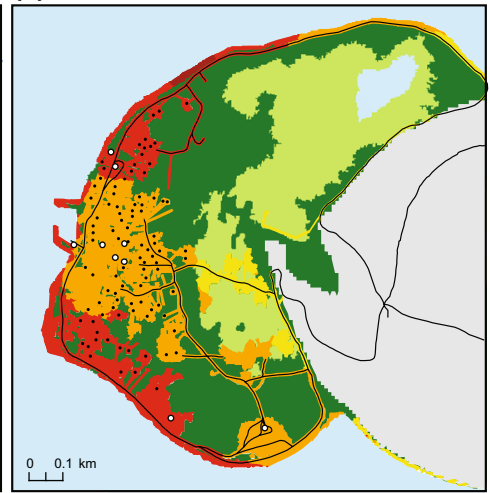

Estimated elapsed time from start of earthquake to:

Initial rise of the first wave Peak height of first wave

a) Leone

16 minutes

20 minutes

b) Nu'uuli

c) Aunu'u

22 minutes

24 minutes

Fig. 13 Maps of estimated pedestrian travel time out of the PMT hazard zone for the American Samoa villages of a Leone, b Nu'uuli, and c Aunu'u, assuming a fast walk travel speed and no travel through forests or wetlands

of distance to this boundary. Other options may be more effective in ensuring individuals can reach safety, such as a sustained evacuation training program to eliminate departure delays and increase pedestrian speeds, the use of vehicles to assist at-risk individuals with limited mobility, or possibly the development of vertical evacuation structures. Community-based outreach programs (e.g., Engstfeld et al. 2010) could be implemented in coastal communities to determine the risk reduction strategies that best serve the local at-risk population and that are tailored to local conditions.

\subsection{Areas for future research}

Given the lack of previous studies to integrate disaster impact assessments, inundation modeling of future threats, and evacuation modeling of at-risk individuals, our analysis identifies several areas of future research to further the understanding of population vulnerability to local tsunamis. The first topic that warrants additional research is the risk perception of at-risk individuals and the influence of potential biases on their intent to prepare for future threats. The idea of tsunamis as credible threats is readily available to local residents given the 2009 event; however, this association may have negative consequences if at-risk individuals anchor their intent to prepare based on their 2009 experience. As noted in this study, the PMT hazard zone is larger than the 2009 impact zone and travel time to safety therefore will be greater. In addition, the shoreline recession that people observed during the 2009 disaster was a unique situation that resulted from a normal fault earthquake. A future tsunami generated by an earthquake near the Tonga Trench may not include a leading trough, and the lack of shoreline recession prior to inundation would deprive at-risk individuals of an environmental cue to evacuate. Therefore, additional research is warranted on how individuals may react to future 
tsunami threats, given their recent experiences with actual tsunami disasters. This type of research is applicable not only to coastal communities in American Samoa, but in other parts of the world that have recently experienced a tsunami yet have other, larger threats that are credible.

Another area for further research is evacuation modeling that incorporates landscape modification as a mitigation option. Previous efforts related to tsunami mitigation analysis have focused on the use of spatial multi-criteria decision analysis (MCDA) to estimate trade-offs in the siting of hardened vertical evacuation structures to provide new refuge options (Wood et al. 2014; Park et al. 2012; Di Mauro et al. 2013; Voulgaris and Aleksejeva 2017). Although hardened vertical evacuation structures may be suitable in some coastal communities, they may not be feasible for smaller and more remote island communities where resources may be more limited, construction and maintenance costs are higher, and at-risk populations may be smaller and more dispersed than those in more developed areas. In many cases, high ground may be available in island communities, but inaccessible due to steep elevation and dense vegetation. Pedestrian evacuation modeling largely has focused on urban areas and to date has overlooked evacuation constraints in more rural areas, such as island communities. More research is warranted on the use of spatial MCDA to identify optimal evacuation corridors based on creating new footpaths through dense vegetation. A related area of research on landscape modification is the potential for offshore reef mitigation and improvement, as modeling summarized in Gelfenbaum et al. (2011) suggests that healthy, rough coral that was wide, high, and without channels reduced tsunami wave heights and onshore inundation areas in American Samoa during the 2009 event.

\section{Conclusions}

Successful evacuations are critical to saving lives from future tsunamis. The objective of this paper is to demonstrate an integrated approach for characterizing population vulnerability to tsunami hazards based on observations of local evacuee behavior from previous disasters, projection of future tsunami threats, and pedestrian evacuation modeling. Based on our case study of American Samoa, we reach several conclusions that bear on future tsunami risk reduction research and application to at-risk communities.

- The use of observed evacuation behavior and demographic data on fatalities from past disasters provides pedestrian evacuation modeling with rich context for interpreting a wide array of modeling scenarios and assumptions.

- Demographics of American Samoa victims of the 2009 Samoa tsunami support existing social science literature, in that there was a disproportionate percentage of victims that were female, older, or of an ethnic minority.

- Differences in actual fatalities from the 2009 disaster and estimated population vulnerability suggest that a single set of modeled travel times to safety does not fully characterize evacuation potential of a large at-risk population due to uncertainties related to population locations, departure delays, and transportation mode.

- Efforts to prepare communities for future tsunamis in American Samoa may need to overcome potential mental anchoring since future threats may have larger wave heights, larger inundation areas, no preceding shoreline recession, larger at-risk populations, and greater distances to safety. 
Acknowledgements This study was supported by the United States Geological Survey (USGS) Land Change Science Program. We thank Elinor Lutu-McMoore of the US National Weather Service and Vinnie Atofau of ASDHS for their continued support of this collaboration. We thank Tim Bodell, Joseph Meredith, and Carl Prendergast for their assistance in providing geospatial data and tsunami-related files for American Samoa. We thank Mara Tongue of the USGS, Elinor Lutu-McMoore, Chip Guard of the US National Weather Service, and anonymous reviewers for their insightful reviews of earlier versions of the article. Any use of trade, product, or firm names is for descriptive purposes only and does not imply endorsement by the US Government.

Open Access This article is distributed under the terms of the Creative Commons Attribution 4.0 International License (http://creativecommons.org/licenses/by/4.0/), which permits unrestricted use, distribution, and reproduction in any medium, provided you give appropriate credit to the original author(s) and the source, provide a link to the Creative Commons license, and indicate if changes were made.

\section{References}

Alabdouli K (2015) Tsunami evacuation: using GIS to integrate behavioral and vulnerability data with transportation modeling. Unpublished doctoral dissertation, Florida State University

American Samoa Department of Commerce (2016) GIS data. Unpublished data provided by American Samoa government, Utulei, American Samoa

American Samoa Department of Homeland Security (2009) Summary intelligence assessment of tsunami fatalities. Unpublished report by Office of Special Investigation, Territorial Emergency Management Coordinating Office

Apatu E, Gregg C, Lindell M, Hillhouse J, Wang L (2015) Survivors perceptions of stakeholders and the 2009 South Pacific tsunami. Disaster Prev Manag 24(5):596-609

Apatu E, Gregg C, Wood N, Wang L (2016) Household evacuation characteristics in American Samoa during the 2009 Samoa Islands tsunami. Disasters 40(4):779-798

Berryman K, Wallace L, Hayes G, Bird P, Wang K, Basili R, Lay T, Pagani M, Stein R, Sagiya T, Rubin C, Barreintos S, Kreemer C, Litchfield N, Stirling M, Gledhill K, Costa C (2015) The GEM faulted earth subduction characterization project, Version 2.0. available from https://www.jcomm.info/index .php?option=com_oe\&task=viewDocumentRecord\&docID=15688. Accessed 29 Sept 2018

Carlos-Arce RS, Onuki M, Esteban M, Shibayama T (2017) Risk awareness and intended tsunami evacuation behaviour of international tourists in Kamakura City, Japan. Int J Disaster Risk Reduct 23:178-192

Charnkol T, Tanaboriboon Y (2006) Tsunami evacuation behavior analysis. Int As Traffic Saf Sci Res 30(2):83-96

Di Mauro M, Megawati K, Cedillos V, Tucker B (2013) Tsunami risk reduction for densely populated Southeast Asian cities: analysis of vehicular and pedestrian evacuation for the city of Padang, Indonesia, and assessment of interventions. Nat Hazards 68(2):373-404

Dudley W, Whitney R, Faasisila J, Fonolua S, Jowitt A, Chan-Kau M (2011) Learning from the victims: new physical and social science information about tsunamis from victims of the September 29, 2009 event in Samoa and American Samoa. Earth Sci Rev 107:201-206

Earthquake Engineering Research Institute (2010) Learning from earthquakes-Samoa earthquake and tsunami of September 29, 2009. EERI Special Report. Available at https://www.eeri.org/site/images/ eeri_newsletter/2010_pdf/Samoa-Rpt.pdf. Accessed 29 Sept 2018

Engstfeld A, Killebrew K, Scott C, Wiser J, Freitag B, El-Anwar O (2010) Tsunami safe haven projectreport for Long Beach, Washington. Department of Urban Design and Planning, College of Built Environments, University of Washington

ESRI (2014) ArcGIS resources-near (analysis), ArcMap near tool. Available via http://resources.arcgi s.com/EN/HELP/MAIN/10.2/index.html\#/Near/00080000001q000000/. Accessed 24 Sept 2015

Fraser S, Leonard G, Johnston D (2013) Intended evacuation behavior in a local earthquake and tsunami at Napier, New Zealand, GNS Science Reports 2013/26, p 55

Fraser S, Wood N, Johnston D, Leonard G, Greening P, Rossetto T (2014) Variable population exposure and distributed travel speeds in least-cost tsunami evacuation modelling. Nat Hazards Earth Syst Sci $14: 2975-2991$

Fritz H, Borrero J, Synolakis C, Okal E, Weiss R, Titov V, Jaffe B, Foteinis S, Lynett P, Chan I, Liu P (2011) Insights on the 2009 South Pacific tsunami in Samoa and Tonga from field surveys and numerical simulations. Earth Sci Rev 107(1-2):66-75 
Gelfenbaum G, Apotsos A, Stevens A, Jaffe B (2011) Effects of fringing reefs on tsunami inundation: American Samoa. Earth Sci Rev 107:12-22

Gica E, Spillane M, Titov V, Chamberlin C, Newman J (2008) Development of the forecast propagation database for NOAA's short term inundation forecast for tsunamis (SIFT). NOAA Technical Memorandum OAR PMEL-139, Pacific Marine Environmental Laboratory Seattle, WA, p 89

Jones J, Ng P, Wood N (2014) The pedestrian evacuation analyst-geographic information systems software for modeling hazard evacuation potential: U.S. Geological Survey techniques and methods, book 11, chap. C9, p 25

Lachman R, Tatsuoka M, Bonk W (1961) Human behavior during the tsunami of May 1960. Science 133:1405-1409

Latcharote P, Leelawat N, Suppasria A, Thamarux P, Imamura F (2018) Estimation of fatality ratios and investigation of influential factors in the 2011 Great East Japan Tsunami. Int J Disaster Risk Reduct 29:37-54

Latitude38 (2009) 'Lectronic latitude-mainly for sale. http://www.latitude38.com/lectronic/lectronicd ay.lasso?date=2009-10-07\#.W5Ft8-hKiUl. Last Accessed 6 Sept 2018

Lay T, Ammon CJ, Kanamori H, Rivera L, Koper K, Hutko A (2010) The 2009 Samoa-Tonga great earthquake triggered doublet. Nature 466(7309):964-968

Leon J, March A (2015) An urban form response to disaster vulnerability-improving tsunami evacuation in Iquique. Environ Plan B Plan Des, Chile. https://doi.org/10.1177/0265813515597229

Lindell M, Prater C, Gregg C, Apatu E (2015) Households' immediate responses to the 2009 American Samoa earthquake and tsunami. Int J Disaster Risk Reduct 12:328-340

Mas E, Suppasri A, Imamura F, Koshimura S (2012) Agent-based simulation of the 2011 Great East Japan earthquake/tsunami evacuation: an integrated model of tsunami inundation and evacuation. J Nat Disaster Sci 34(1):41-57

Mostafizi A, Wang H, Cox D, Cramer LA, Dong S (2017) Agent-based tsunami evacuation modeling of unplanned network disruptions for evidence-driven resource allocation and retrofitting strategies. Nat Hazards 88(3):1347-1372

Murakami H, Takimoto K, Pomonis A (2012) Tsunami evacuation process and human loss distribution in the 2011 Great East Japan Earthquake-a case study of Natori City, Miyagi Prefecture, 15WCEE, Lisbon, Portugal

National Geophysical Data Center/World Data Service (NGDC/WDS) (2017) Global historical tsunami database. National Geophysical Data Center, NOAA

National Oceanic and Atmospheric Administration Office for Coastal Management (NOAA OCM) (2017) High-resolution land cover data. Coastal Change Analysis Program (C-CAP). http://coast.noaa.gov/ ccapftp/. Last Accessed 11 May 2017

National Research Council (2011) Tsunami warning and preparedness-an assessment of the U.S. Tsunami Program and the Nation's preparedness efforts, Committee on the Review of the Tsunami Warning and Forecast System and Overview of the Nation's Tsunami Preparedness, National Academy of Sciences, p 266

Park S, van de Lindt J, Gupta R, Cox D (2012) Method to determine the locations of tsunami vertical evacuation shelters. Nat Hazards 63:891-908

Pongponrat K, Ishii K (2018) Social vulnerability of marginalized people in times of disaster: case of Thai women in Japan Tsunami 2011. Int J Disaster Risk Reduct 27:133-141

Reese S, Bradley B, Bind J, Smart G, Power W, Sturman J (2011) Empirical building fragilities from observed damage in the 2009 South Pacific tsunami. Earth Sci Rev 107:156-173

Roeber V, Yamazaki Y, Cheung K (2010) Resonance and impact of the 2009 Samoa tsunami around Tutuila, American Samoa. Geophys Res Lett 37(21):L21604. https://doi.org/10.1029/2010GL044419

Soule R, Goldman R (1972) Terrain coefficients for energy cost prediction. J Appl Physiol 32:706-708

Takabatake T, Shibayama T, Esteban M, Ishii H, Hamano G (2017) Simulated tsunami evacuation behavior of local residents and visitors in Kamakura, Japan. Int J Disaster Risk Reduct 23:1-14

Tobler W (1993) Three presentations on geographical analysis and modeling-non-isotropic geographic modeling. Speculations on the geometry of geography; and global spatial analysis. UCSB. National Center for Geographic Information and Analysis Technical Report 93-1. Available at http://www.ncgia .ucsb.edu/Publications/Tech_Reports/93/93-1.PDF. Accessed 19 July 2010

Tversky A, Kahneman D (1971) Belief in the law of small numbers. Psychol Bull 76(2):105-110

Tversky A, Kahneman D (1974) Judgment under uncertainty-heuristics and biases. Science 185(4157):1124-1131

United States Army Corps of Engineers (2011) Sea-level change considerations for civil works programs. Circular No. 1165-2-212. Available at https://cdm16021.contentdm.oclc.org/digital/collection/p1602 1 coll9/id/88/rec/1. Accessed 29 Sept 2018 
United States Census Bureau (2011) American FactFinder. Available at http://factfinder2.census.gov/faces/ nav/jsf/pages/index.xhtml. Accessed 1 May 2011

United States Census Bureau (2017) 2010 overview. Available at https://www.census.gov/history/www/ through_the_decades/overview/2010_overview_1.html. Accessed 29 Sept 2018

United States Department of Agriculture (2017) Geospatial Data Gateway. Available at http://datagatewa y.nrcs.usda.gov/. Accessed 1 July 2017

Voulgaris G, Aleksejeva J (2017) Spatiotemporal identification of potential tsunami vertical evacuation sites: a case study of Shizuoka City. PLOS Curr Disasters, Japan. https://doi.org/10.1371/currents.dis. e66442ce2b19de55532457d967d9645d

Wood N, Schmidtlein M (2013) Community variations in population exposure to near-field tsunami hazards as a function of pedestrian travel time to safety. Nat Hazards 65(3):1603-1628

Wood N, Burton C, Cutter S (2010) Community variations in social vulnerability to Cascadia-related tsunamis in the U.S. Pacific Northwest. Nat Hazards 52(2):369-389

Wood N, Jones J, Schelling J, Schmidtlein M (2014) Tsunami vertical-evacuation planning in the U.S. Pacific Northwest as a geospatial, multi-criteria decision problem. Int J Disaster Risk Reduct 9:68-83

Wood N, Jones J, Spielman S, Schmidtlein M (2015) Community clusters of tsunami vulnerability in the US Pacific Northwest. Proc Natl Acad Sci 112(17):5354-5359

Yamazaki Y, Kowalik Z, Cheung K (2009) Depth-integrated, non-hydrostatic model for wave breaking and runup. Int J Numer Methods Fluids 61(5):473-497

Yamazaki Y, Cheung K, Kowalik Z (2011) Depth-integrated, non-hydrostatic model with grid nesting for tsunami generation, propagation, and run-up. Int J Numer Methods Fluids 67(12):2081-2107

Yun N, Hamada M (2012) Evacuation behaviors in the 2011 Great East Japan earthquake. J Disaster Res 7(7):458-467

\section{Affiliations}

\section{Nathan Wood ${ }^{1}$ (D) . Jeanne M. Jones ${ }^{2} \cdot$ Yoshiki Yamazaki $^{3} \cdot$ Kwok-Fai Cheung $^{3}$. Jacinta Brown ${ }^{4}$. Jamie L. Jones ${ }^{2} \cdot$ Nina Abdollahian ${ }^{2}$}

Jeanne M. Jones

jmjones@usgs.gov

Yoshiki Yamazaki

yoshikiy@hawaii.edu

Kwok-Fai Cheung

cheung@hawaii.edu

Jacinta Brown

j.brown@asdhs.as.gov

Jamie L. Jones

jamiejones@usgs.gov

Nina Abdollahian

nabdollahian@usgs.gov

1 Western Geographic Science Center, United States Geological Survey, 2130 SW 5th Avenue, Portland, OR 97201, USA

2 Western Geographic Science Center, United States Geological Survey, 345 Middlefield Road, Menlo Park, CA 94025, USA

3 University of Hawai'i at Manoa, 2540 Dole Street, Holmes Hall 402, Honolulu, HI 96822, USA

4 American Samoa Department of Homeland Security, PO Box 4567, Pago Pago, AS 96799, USA 